\title{
Scientific Error and Error Handling
}

\author{
Sarah Machado-Marques \\ Department of Mathematics, University of Toronto \\ sarah.marques@mail.utoronto.ca
}

\author{
Paul Patton \\ IHPST, University of Toronto \\ paul.patton@mail.utoronto.ca
}

\section{Keywords}

theoretical scientonomy, observational scientonomy, scientific error, theory rejection, sufficient reason, pulsar planet, Piltdown Man, exoplanet, Sophie Jamal, monarch butterfly

\begin{abstract}
Error is a common part of scientific practice, which must be accounted for by scientonomy. A scientific error occurs when an agent accepts a theory that should not have been accepted given that agent's employed method. One might suspect that the handling of scientific error seems to violate the theory rejection theorem according to which a theory becomes rejected only when other theories that are incompatible with the theory become accepted, because it appears as though a theory isn't replaced by anything. Here, we analyze several instances of scientific error and show that error handling, when properly analyzed, is fully consistent with the theory rejection theorem. We show that instances of scientific error typically involve the rejection of an erroneous conclusion as well as one or more of the premises of the argument that leads to that erroneous conclusion. In most cases, first-order propositions of the original erroneously accepted theory are replaced by other first-order propositions incompatible with them. In some cases, however, first-order propositions are replaced by second-order propositions asserting the lack of sufficient reason for accepting these first-order propositions. In both cases, such a replacement is fully consistent with the theory rejection theorem.
\end{abstract}




\section{Introduction}

In 1991, a team of three British astronomers from the University of Manchester announced a remarkable discovery in the pages of the prestigious journal Nature (Bailes, Lyne, \& Shemar, 1991). For the first time in history, they had detected a planet outside our solar system. The putative planet was orbiting a pulsar: a rapidly rotating neutron star emitting regularly recurring radio pulses, designated PSR1829-10 (Anonymous, 1992). The research team of Lyne, Bailes, and Shemar (1991) measured periodic variations in the interval between the pulses as received on Earth. They found a cyclic variation in the arrival times of the pulses exhibiting a period close to six months (Lyne $\&$ Bailes, 1992). They took this as evidence that a planet was revolving around the pulsar. The gravitational pull of the planet was influencing the movement of the pulsar, causing the cyclic variation in the observed interval between its pulses (Anonymous, 1992).

The research group's acceptance of the existence of the pulsar planet was evident through their willingness to publish a letter in Nature and arrange to announce the discovery at a meeting of the American Astronomical Society (Anonymous, 1992). But before they were able to do so, the research group found a mistake in their calculations. Although their measurements were properly taken, their data analysis software did not properly correct for the fact that the Earth's orbit around the sun is not circular. The variations in the timing of the pulsar's pulses were actually due to the motion of the Earth, rather than to the gravitational pull of an alien planet. The researchers knew that such a correction should have been part of their procedure and that their conclusion of the existence of a planet should not have been accepted by their own method. At the meeting, they announced that their claim was mistaken. In a published letter to Nature, they retracted their findings (Lyne \& Bailes, 1992). Such instances of error are an occasional but inevitable occurrence in scientific practice (Brainard \& You, 2018).

At the moment, scientonomy does not have an explanation of how these cases of erroneous acceptance are handled. The issue of error was first raised in an open question by Maxim Mirkin and Sinan Karamehmetoglu in 2018. They were concerned that, in cases of error, it appeared as though a theory was simply being removed from the mosaic due to its being recognized as an error without being replaced by another theory. For example, when the pulsar planet theory was rejected, it was not replaced by an incompatible theory asserting the absence of a planet circling the pulsar. In fact, it was not replaced by any claim about whether or not a planet orbited the pulsar at all. This seems to violate the theory rejection theorem which states that "A theory becomes rejected only when other theories that are incompatible with the theory become accepted." (Barseghyan, 2015, pp. 168). Since the theory rejection theorem is a deductive consequence of the first law and the compatibility corollary (Fraser \& Sarwar, 2018, pp. 71, 74-75) and since the compatibility corollary itself simply follows from the definition of compatibility, such cases of error handling can also potentially violate the first law, according to which "an element of the mosaic remains in the mosaic unless replaced by other elements" (Barseghyan, 2015, pp. 123).

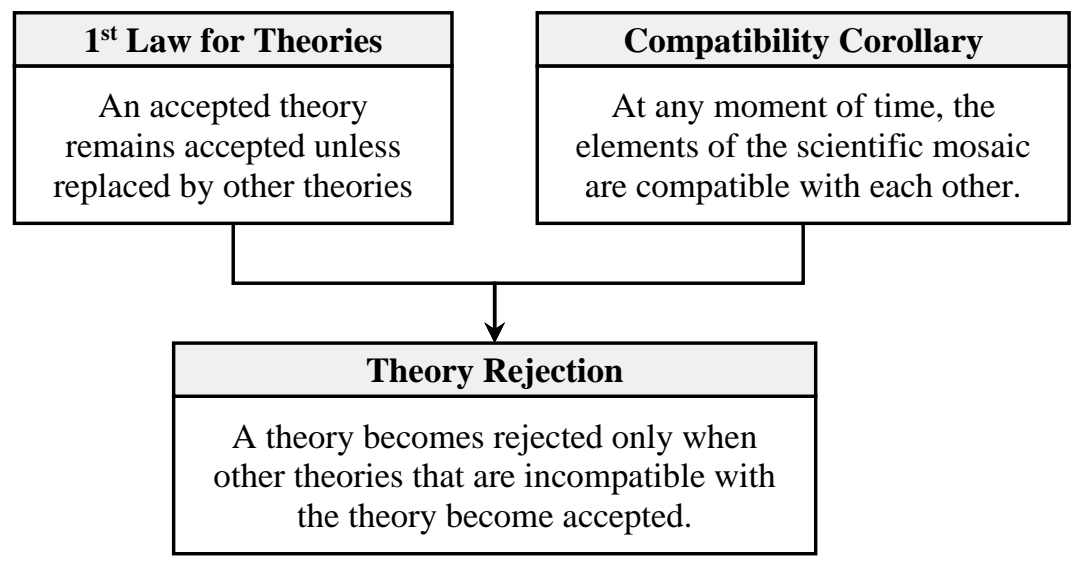

In this paper, we will show that when instances of error handling are properly understood, they are no different from any other case in which the acceptance of a new theory results in the rejection of the incompatible originally accepted theory from the mosaic. Instances of error handling provide no reason to question the theory rejection 
theorem or the first law. To demonstrate this, we will need to provide a more detailed analysis of the respective scientific practice than has previously been attempted within scientonomy. To this end, we will first offer a definition of what we mean by error and explain how our usage differs from some other common usages of the term. Then, we will analyze several cases from the history of science that fit our definition of error. We will show that, despite appearances, the occurrence of error handling in scientific practice accords with the theory rejection theorem currently accepted in scientonomy.

\section{What is Error?}

The word "error" has often been used by historians and philosophers of science to denote once accepted but now rejected theories; these old theories are said to be "erroneous" as they are in conflict with our currently accepted theories. Consider, for example, the rejected geocentric model of the universe, in which the terrestrial globe was held to be stationary at the center of the universe. Some would regard this now-rejected model as an error, as it conflicts with the modern heliocentric theory, in which the Earth is one of eight known major planets revolving around the sun. Such an absolute notion of error is abundant in the literature and is summed up in Allchin's definition of the term, according to which, error is a false claim, interpreted as true and justified (Allchin, 2001).

An absolute sense of error is not the sense we wish to consider here because we do not believe it is possible or useful for scientonomic purposes to take up such an absolute point of view. We can never be certain that any or all of our current scientific theories will not also someday become rejected in favor of new theories (Karamehmetoglu \& Mirkin, 2018). Thus, we characterize such a theory simply as rejected with no implications about absolute error.

The sense of error we are interested in is one that can be judged not from some future perspective, but rather from the perspective of the respective historical actor in accordance with the method employed by that actor at that time. On this account of error, acceptance of the geocentric system was not an error, since that acceptance was in accord with the method of theory assessment then employed, and a plausible alternative account involving a moving planetary Earth was not then available. In contrast, the case of the pulsar planet is an instance of error, since it was recognized that the astronomers, by their own standards, had committed an error. More generally, we can state that an error occurs when an epistemic agent, such as a research group or a scientific community, mistakenly accepts a theory based on a belief that the conditions of their employed method were satisfied, when those conditions actually have not been satisfied. This definition identifies the action of acceptance as erroneous according to the employed method of the time, rather than from some future perspective unattainable for the agent in question. We can summarize this concept of error in a formal scientonomic definition:

\begin{tabular}{|c|}
\hline Error $\equiv$ \\
\hline An epistemic agent is said to commit an error if the \\
agent accepts a theory that should not have been \\
accepted given that agent's employed method. \\
\hline
\end{tabular}

This definition of error ensures that error is agent-relative and avoids the anachronistic evaluation of past science from the perspective of contemporary science. It disallows an absolute sense of the term by abiding by the law of theory acceptance (Patton, Overgaard, \& Barseghyan, 2017). When a theory is erroneously accepted, the agent believes it has satisfied the requirements of their employed method when, in fact, it has not.

A common distinction made in the literature is that of two forms of error: honest error and misconduct (Resnik \& Stewart, 2012). To facilitate this discussion, we need to consider two communal or individual agents, which are, typically, distinct from one another: a theory-creator, who offers a theory for assessment, and a theoryassessor responsible for assessing the theory for possible acceptance. Sometimes a theory-creator may make honest mistakes in their scientific practice, such as being unaware of a miscalculation or malfunctioning of scientific instruments (Ewuoso, 2018). Misconduct occurs when such an agent intentionally misrepresents their 
findings, such as by concealing that they have fabricated or manipulated data, all the while being aware that their theory doesn't satisfy the requirements of the method employed by their community. While this distinction is important for ethical purposes, it is not relevant to the scientonomic analysis we will present here because, in our analysis, error is agent-relative. We are primarily interested in the perspective of the agent responsible for theory assessment. The assessing agent will be unaware of any fraudulent actions of the theory-creator agent offering the theory for assessment, in the same way as they will be unaware that honest error has occurred (although in the case of honest error the theory-creator agent may be identical with the assessing agent). Importantly, it is the assessing agent who makes the error in concluding that the requirements of the employed method have actually been met. As for the perspective of a fraudulent agent offering their "findings" to the community, there is no error to speak of, since they are aware of their fraud from the outset and, thus, cannot be said to have accepted these "findings" in the scientonomic sense.

With this definition of error in hand, we can now show that the actual practice of error handling in science is compatible with the currently accepted scientonomic theory. We will consider four historical episodes of error handling and will show how they all comply with the theory rejection theorem. Since a theory is currently understood as a set of propositions (Sebastien, 2016), we will focus on individual propositions of these theories and show how each of the rejected propositions of the erroneously accepted theory was replaced by a respective incompatible proposition, as dictated by the theory rejection theorem.

\section{Pulsar Planet}

The basic story of the pulsar planet episode has already been presented in the introduction. In its simplest terms, astronomers Bailes, Lyne, and Shemar can be said initially to have accepted the theory, "It is likely that there is a planet orbiting the pulsar PSR1829-10" (Bailes, Lyne, \& Shemar, 1991) and later to have rejected that proposition, seemingly without replacing it with anything else in their mosaic (Lyne \& Bailes, 1992).

The recent work of Palider (2019) shows how a more careful analysis can be conducted within the context of scientonomy. Palider (2019) has argued that when analyzing a theory, we must consider the reasons that warranted the acceptance of a proposition. When analyzed in this way, we can recognize that the theory at issue actually consists of a large set of propositions, linked together by inferences that form a complex argument with the proposition concerning the presence of a planet as its conclusion. Such an analysis is essential for understanding why the handling of the error, despite appearances, can in fact be readily accounted for by known scientonomic laws. We can begin by summarizing Bailes, Lyne, and Shemar's (1991) argument textually and then diagrammatically.

Pulsars are collapsed remnants of massive stars and are as dense as an atomic nucleus. Such stars are made primarily of neutrons, so they are also called neutron stars. They emit pulses of radio waves at short regular intervals ranging from milliseconds to seconds. The regularity of this interval has a precision comparable to an atomic clock (Morison, 2008, pp. 250-259). In 1991, a team of three astronomers, observing the pulsar designated PSR1829-10 with the radio telescope at the Jodrell Bank radio observatory in England, discovered that this pulsar exhibited a periodic oscillation in the interval between its pulses. The expected intrinsic regularity of a pulsar meant that this oscillation required an explanation. Although they did not explicitly mention it in their paper, the researchers presumably ruled out instrumental error as the cause of this unexpected finding. Using mathematical models and knowledge of the behavior of other pulsars, the researchers ruled out causes of the oscillation internal to the neutron star, such as wobbling of its magnetic field or oscillations in its fluid interior (Bailes, Lyne, \& Shemar, 1991). This left the most probable remaining cause to be the Doppler Effect.

The Doppler Effect is the apparent change in the frequency of an emission due to relative motion between the source and the receiver (Morison, 2008, pp. 135-142). If the oscillation were due to the Doppler Effect, it implied oscillatory movement. This movement could either be a movement of the radio telescope, affixed to the Earth, or the pulsar. The researchers believed that their computer software algorithm corrected for the effects of the movement of the Earth on the pulsar's pulses. From these premises the researchers concluded that the oscillatory 
movements were movements of the pulsar through space. An object would exhibit an oscillatory movement through space if it were influenced by the gravitational pull of another object orbiting it. Based on this argument, the astronomers concluded that there was sufficient reason (Palider, 2019) to accept that such an object existed and calculated that it was a planet ten times as massive as Earth (Bailes, Lyne, \& Shemar, 1991). To reiterate: their acceptance of this conclusion is indicated by their willingness to submit their findings for publication in Nature. The most critical features of the astronomers' argument that it is likely that there is a planet orbiting pulsar PSR1829-10 can be summarized as follows in the following diagram:

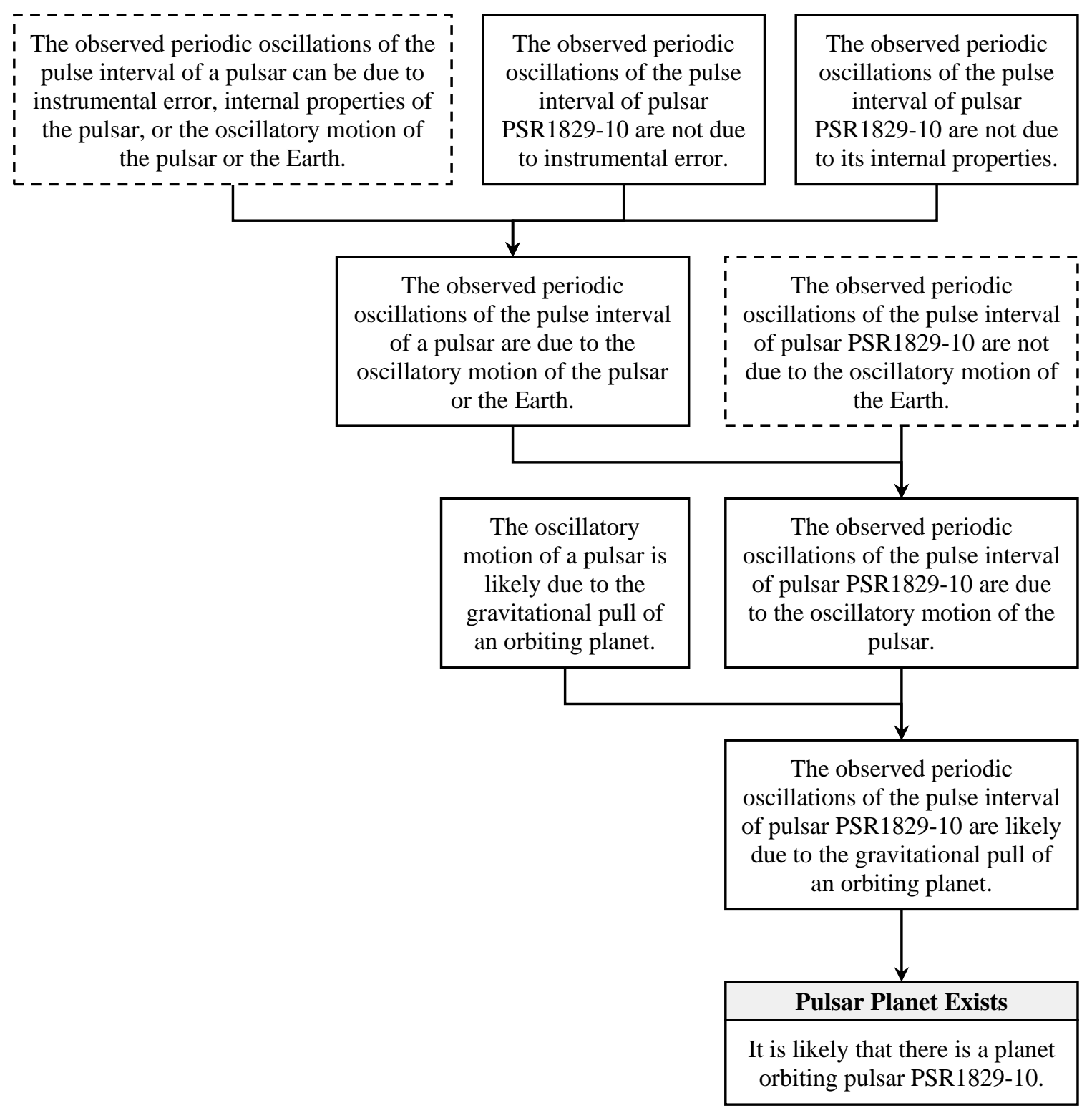

The diagrammed argument, and the researchers' published paper, provides a sketch of the full set of arguments and inferences supporting their conclusion that a planet orbits pulsar PSR1829-10. Each of the stated premises functions as the conclusion of an argument, constituted by the technical details of the researchers' work, which involved mathematical models, computer software, and the properties of the radio telescope itself and its associated electronics. This work provided the researchers sufficient reason to accept each premise of the argument. An important unstated premise is that all this technical work was free of significant mistakes. Given our improved grasp of the astronomers' theory as a set of propositions organized as an argument providing sufficient reason for their conclusion, we are now in a position to analyze their response to error. 
Upon carefully scrutinizing their work, the astronomers came to realize that their technical work was not free of significant mistakes. They discovered that their data analysis algorithm did not properly account for the fact that the Earth's orbit around the sun is an ellipse and not a circle. When appropriate corrections were made, the oscillations in the interval between PSR1829-10's pulses were fully accounted for. This new discovery led the researchers to reject their previous conclusion about the existence of the pulsar planet. Now, how exactly was this rejection in accord with the theory rejection theorem? According to the theorem, a theory can only be rejected

Note that in this case, the assessing epistemic agent in question was the research group itself, rather than some larger community. The brevity of the incident did not allow for its assessment by a broader community.

from the mosaic when it is replaced by another theory incompatible with it. It might be tempting to suggest that the rejected propositions of the original argument (highlighted on the diagram below) were rejected since they were found incompatible with the discovery that the oscillations of the pulse interval of pulsar PSR1829-10 are due to the oscillatory motion of the Earth:

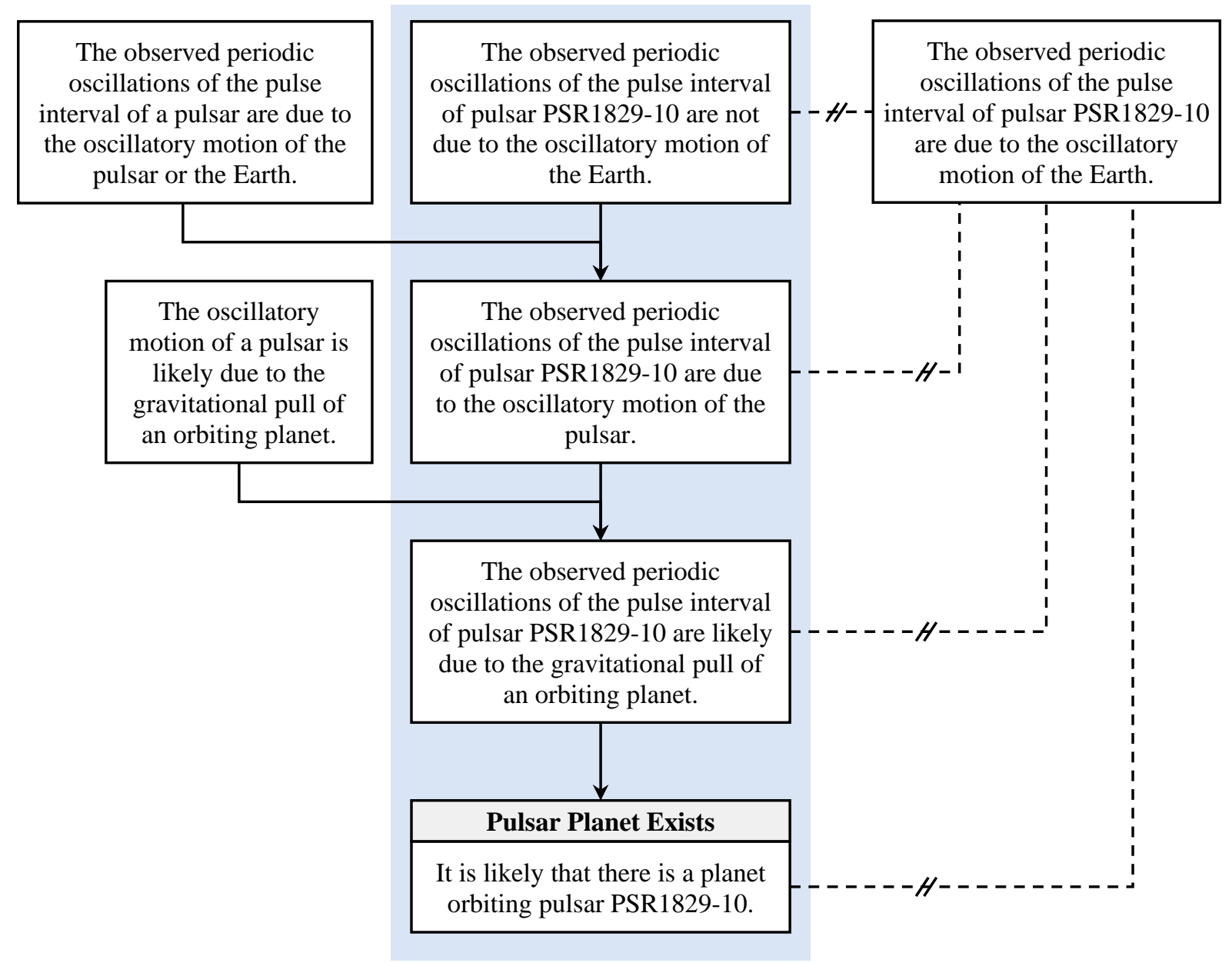

Yet, such a conclusion would be somewhat simplistic and misleading. To ascertain that the rejection of the original propositions was in accord with the theory rejection theorem, we have to show how each of the propositions of the original argument for the existence of the pulsar planet was replaced with a proposition incompatible with it. This isn't difficult to do for every rejected proposition of the original argument except for the final conclusion, since all rejected propositions of the original arguments except for the conclusion were replaced by their negations. For instance, the proposition "The observed periodic oscillations of the pulse interval of pulsar PSR1829-10 are not due to the oscillatory motion of the Earth" was replaced by the incompatible proposition "The observed periodic oscillations of the pulse interval of pulsar PSR1829-10 are due to the oscillatory motion of the Earth', while the proposition "The observed periodic oscillations of the pulse interval of pulsar PSR1829- 
10 are due to the oscillatory motion of the pulsar" was replaced by the incompatible proposition "The observed periodic oscillations of the pulse interval of pulsar PSR1829-10 are not due to the oscillatory motion of the pulsar" and so on. All these new propositions became accepted by the agent as indicated by their retraction (Lyne \& Bailes, 1992) and their admission of error in a public presentation at the American Astronomical Society conference (Anonymous, 1992). Importantly, these were all replacements of some first-order propositions with other first-order propositions.

As for the conclusion of the original argument - the proposition "It is likely that there is a planet orbiting pulsar PSR1829-10" - it wasn't replaced by any other first-order proposition. We cannot say that it was replaced by a claim that there is no such planet, since rejection of an argument for the existence of a planet is not at all the same thing as demonstrating its absence. Nor can we say that it was replaced by "It is not likely that there is a planet orbiting pulsar PSR1829-10". In 1991, astronomers had no prior knowledge of planets beyond our solar system and were in no position to assess the prior likelihood or unlikelihood of a planet existing in some particular situation. The apparent lack of any first-order proposition that could replace the original proposition in the mosaic is what made Mirkin and Karamehmetoglu (2018) suspect that the episode violates the first law of scientific change. In contrast, our analysis shows clearly that the proposition was, indeed, replaced with something, as the law specifies. What it was replaced with is a second-order proposition stating that there is no sufficient reason for accepting the proposition "It is likely that there is a planet orbiting pulsar PSR1829-10":

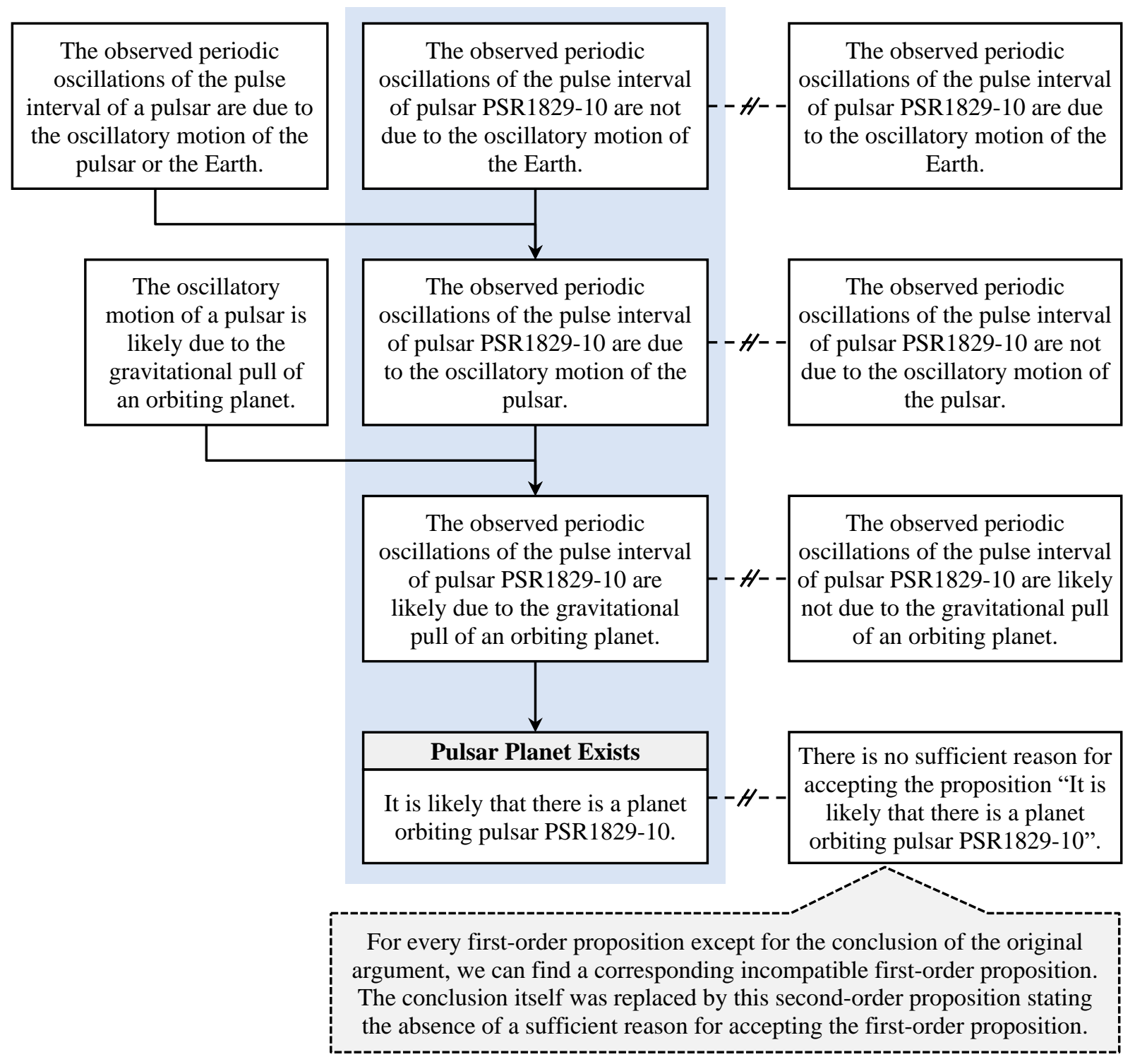


This second-order proposition itself follows from two premises - the idea that the proposition "The observed periodic oscillations of the pulse interval of pulsar PSR1829-10 are not due to the oscillatory motion of the Earth" was the only reason for accepting the existence of the pulsar planet and that "The observed periodic oscillations of the pulse interval of pulsar PSR1829-10 are not due to the oscillatory motion of the Earth" is not acceptable:

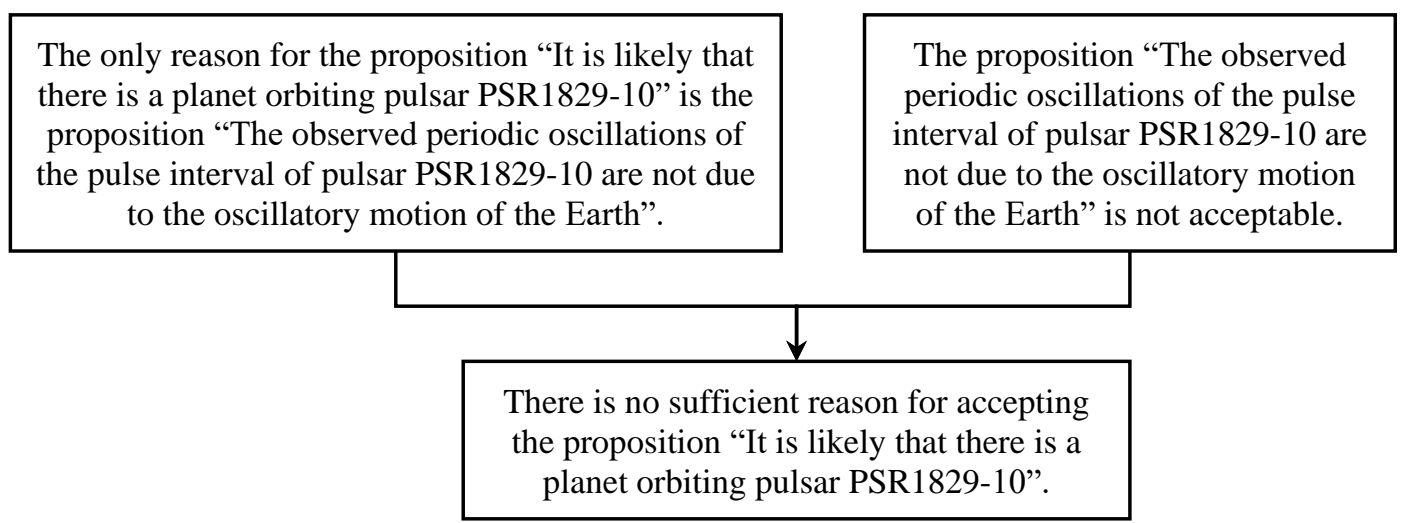

But how can first- and second-order propositions be incompatible? Since compatibility/incompatibility of mosaic elements depends crucially on the mosaic's criteria of compatibility (Fraser \& Sarwar, 2018), there will be no universal answer to this question; nor do we need one. What's important for us is the very fact that sometimes second-order propositions can push first-order propositions out of a mosaic, which means that such an incompatibility is possible. Specifically, the case of the pulsar planet suggests that the respective epistemic agent accepted a relatively straightforward compatibility criterion stating that first-order proposition $A$ is incompatible with the second-order proposition "There is no sufficient reason for accepting $A$ ". As we will show, all cases under consideration in this paper can be explained by assuming that the respective agents employed similar compatibility criteria that rendered the proposition $A$ incompatible with the proposition "There is no sufficient reason for accepting $A$ ".

In short, the propositions of the original argument were replaced by new incompatible propositions - in full accordance with the theory rejection theorem and the first law of scientific change. No modification or reinterpretation of these laws is required to account for this case of error handling.

There is good reason to think that such compatibility criteria that allow for evaluating the compatibility between first- and second-order propositions are common in epistemic practice. Consider, for example, the incompatibility between theism and agnosticism: the former is a first-order statement about God's existence while the latter is a second-order statement saying that we cannot know whether God exists or not. Clearly, we think of the two as incompatible, which shows that we have a way of ascertaining whether such firstand second-order propositions are compatible or incompatible.

\section{Dr. Sophie Jamal and the Treatment of Osteoporosis}

Dr. Sophie Jamal was a respected medical school professor at the University of Toronto with a focus on research in osteoporosis at the Women's College Hospital. She held a position of prominence as the research director of the Centre for Osteoporosis and Bone Health and the division head of endocrinology and metabolism (Dyer, 2015). As a primary author of about 50 papers, Jamal was regarded as a talented professional and a person of high moral standing by her colleagues, even receiving the Canadian Society of Endocrinology and Metabolism's Young Investigator Award in 2012 (Dyer, 2015; Shuchman, 2016). Jamal et al. (2011)'s study, published in the Journal of the American Medical Association (JAMA), purported to show impressive evidence that applying nitroglycerine ointment to postmenopausal women had a positive effect on bone health (Shuchman, 2016). The ointment was claimed to increase bone mineral density and decrease bone reabsorption over time (Dyer, 2015). There were prior reasons for supposing that nitroglycerine might be useful as a treatment for preventing osteoporosis related bone fractures in post-menopausal women. Nitroglycerine was already known to stimulate bone formation and inhibit bone re-absorption. Additionally, it was inexpensive and widely available. Dr. Jamal and her colleagues 
reported a double-blind randomized placebo-controlled trial involving 243 post-menopausal women, with the experimental group using nitroglycerine ointment at bedtime for 24 months (Jamal et al. 2011). The women's bone mineral density at a number of locations in the body, and in their urine, was examined for evidence of bone reabsorption. These measures would allow the researchers to determine the effects of nitroglycerine on the density, structure, and strength of the women's bones. On the basis of their analysis of the data, Jamal and her team claimed that women in the nitroglycerine ointment group exhibited a statistically significant increase in bone mineral density, decrease in bone reabsorption, and increased indices of bone strength over the control group. Thus, they argued that the study provided a new reason to believe that nitroglycerine ointment may be useful as a preventative treatment for osteoporosis related bone fractures in postmenopausal women (Jamal et al. 2011). The finding attracted brief notice in the medical press in 2011 and the success secured her and her team more funding to continue pursuing the question of the effects of nitrates on osteoporosis (Dyer, 2015). Evidence that the community accepted this theory can be found in the attention the research evoked, and the awarding of additional funding for further research (Dyer, 2015).

Dr. Jamal's argument is best reconstructed by focusing on its second-order propositions:

! A study provides a reason for the proposition "Nitroglycerine ointment may be useful for the prevention of osteoporosis related bone fractures in postmenopausal women" only if:

- the effects of nitroglycerine ointment on bone density, structure, and strength were tested on postmenopausal women in a double-blind randomized placebo-controlled trial;

and

- the women in the nitroglycerine ointment group exhibited a statistically significant increase in bone mineral density, decreased bone reabsorption, and increased indices of bone strength over the placebo control group.

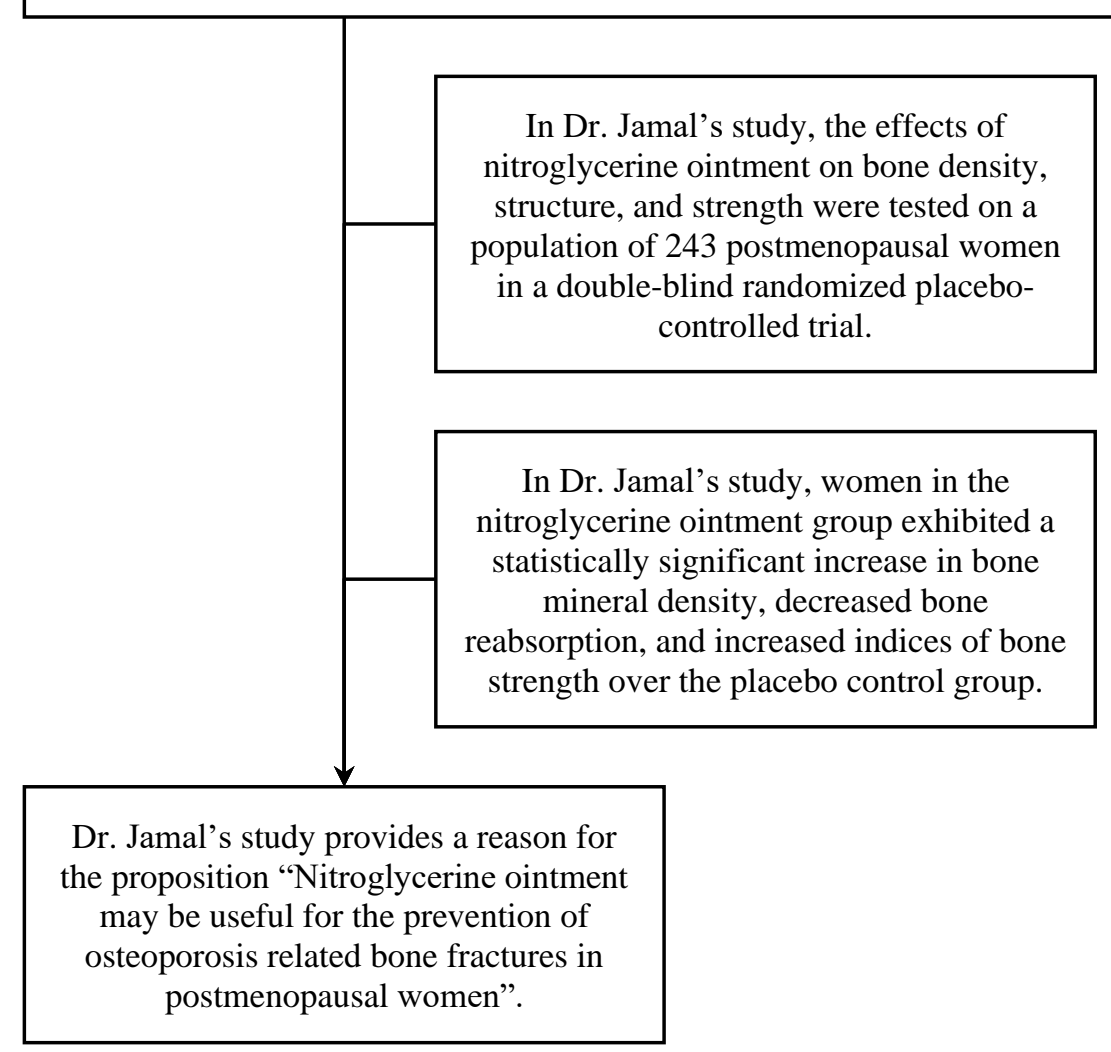

The basic premise of the argument is a method for evaluating the claim that nitroglycerine ointment may be useful for the prevention of osteoporosis related bone fractures in postmenopausal women. The two other premises state what was accomplished in Dr. Jamal's study and are meant to show that the criteria outlined in the first premise were satisfied. The conclusion of the argument is a statement that the study provides a new reason to accept that 
nitroglycerine ointment may be useful for the prevention of osteoporosis related bone fractures in post-menopausal women.

During a follow-up study, Jamal's coauthors, Dr. Steven Cummings and Dr. Richard Eastell, became suspicious that she was fabricating data. They theorized that the proper procedures of statistical analysis had not been followed after noticing her data analysis was inconsistent with the raw data they sent (Shuchman, 2016). Cummings and Eastell reported their concerns and Jamal's work became the subject of an inquiry by the University of Toronto and the Women's College Hospital (Shuchman, 2016). The misconduct inquiry concluded that Jamal had violated the accepted norms regarding proper conduct in the scientific process by altering data in her study such that "the findings were made to look more positive than they were" (Dyer, 2015). The paper, which had been cited 30 times, was later retracted by the JAMA (Dyer, 2015; Palus, 2015). As a result of her falsification, Jamal's other studies were called into question. Researchers attempted to replicate the results of two other studies using data from the study's central repository. Their analyses did not match Jamal's and since then, two of Jamal's other papers have also been retracted (Shuchman, 2016).

As can be seen in the diagram below, the rejected propositions of Dr. Jamal's original argument were all replaced by their direct negations:

! A study provides a reason for the proposition "Nitroglycerine ointment may be useful for the prevention of osteoporosis related bone fractures in postmenopausal women" only if:

- the effects of nitroglycerine ointment on bone density, structure, and strength were tested on postmenopausal women in a double-blind randomized placebo-controlled trial; and

- the women in the nitroglycerine ointment group exhibited a statistically significant increase in bone mineral density, decreased bone reabsorption, and increased indices of bone strength over the placebo control group.

In Dr. Jamal's study, the effects of nitroglycerine ointment on bone density, structure, and strength were tested on a population of 243 postmenopausal women in a double-blind randomized placebocontrolled trial.

In Dr. Jamal's study, women in the nitroglycerine ointment group exhibited a statistically significant increase in bone mineral density, decreased bone reabsorption, and increased indices of bone strength over the placebo control group.

Dr. Jamal's study provides a reason for the proposition "Nitroglycerine ointment may be useful for the prevention of osteoporosis - - t/ related bone fractures in postmenopausal women".
Dr. Jamal falsified or fabricated data and then used that data for statistical analysis in the nitroglycerine study to make them appear significant.

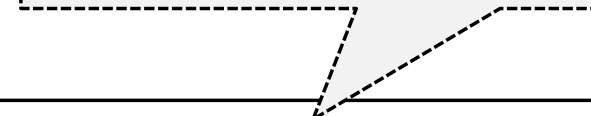

In Dr. Jamal's study, women in the nitroglycerine ointment group did not exhibit a statistically significant increase in

bone mineral density, decreased bone reabsorption, and increased indices of bone strength over the placebo control group.

Dr. Jamal's study provides no reason for the proposition "Nitroglycerine ointment may be useful for the prevention of osteoporosis related bone fractures in postmenopausal women". 
Specifically, it is now accepted that, in Dr. Jamal's study, women in the nitroglycerine ointment group did not actually exhibit a statistically significant increase in bone mineral density, decreased bone reabsorption, or increased indices of bone strength over the placebo control group, for it was determined that Dr. Sophie Jamal fabricated her data and then used that data for statistical analysis. As a result, it is also accepted by the community that the study provides no new reason to suppose that nitroglycerine ointment may be useful for the prevention of osteoporosis related bone fractures in post-menopausal women. One indication of this acceptance is JAMA's retraction of Jamal's 2011 study. Since all of the rejected propositions of Dr. Jamal's original argument were replaced by new theories incompatible with them, this case of error handling is in full accord with the theory rejection theorem.

\section{Monarch Misidentification}

In 1975, zoologists N. Nageswara Rao and A. S. Murty, working at Andhra University in Visakhapatnam, India, published a study aimed at determining the number of chromosomes of the monarch butterfly (Danaus plexippus). Their result was published in a widely cited paper (Price, 2017; Rao \& Murty, 1975). Rao and Murty (1975) knew that when a procedure called a chromosome squash was performed using testicular cells from an animal, the animal's chemically stained chromosomes were rendered visible under the microscope for counting. They collected butterflies of the genus Danaus in Guntur, India, which they identified as monarchs (Danaus plexippus). They performed the chromosome squash on samples from these animals and counted 30 chromosomes (Rao \& Murty, 1975), and from these results, concluded that butterflies of the species Danaus plexippus have 30 chromosomes. This conclusion appears to have been accepted by the broader community of genetics researchers as evidenced by the fact that the paper has been cited numerous times (Price, 2017; Hamm, 2017). The argument they used to provide sufficient reason for this conclusion can be summarized below:

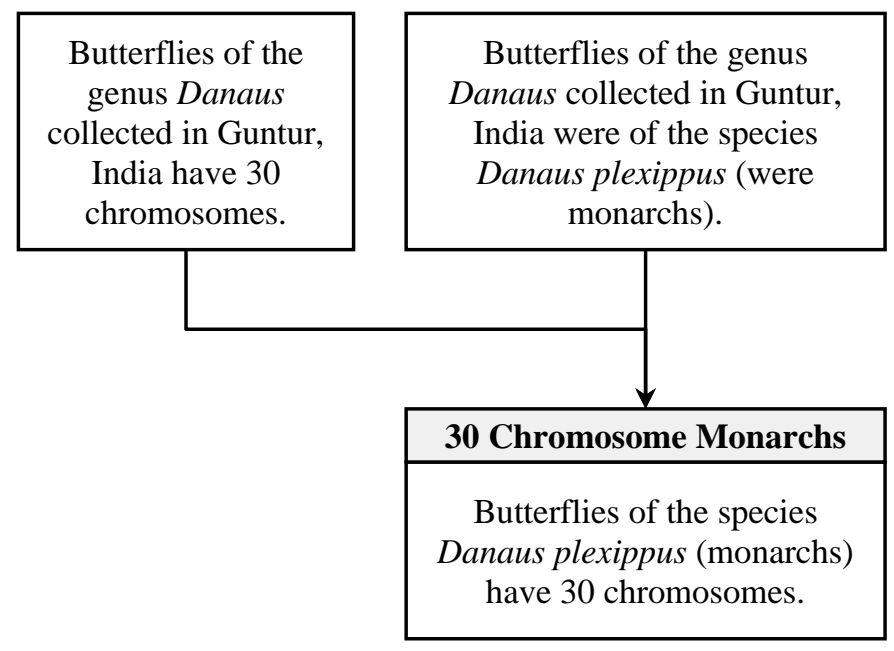

Note that, as in the pulsar planet case, each premise of the argument for the theory that the monarch butterfly has 30 chromosomes is itself the conclusion of unstated technical arguments, concerning such things as the proper conduct of the chromosome squash preparation procedure, and proper taxonomic identification of the species under study. An unstated premise of the argument that the Monarch butterfly has 30 chromosomes is that these technical arguments were free of mistakes.

During his studies, Christopher Hamm, a researcher at the University of Kansas in the United States claimed to notice an error in Rao and Murty's research (Price, 2017; Hamm, 2017). Hamm found that the butterflies Rao and Murty studied could not possibly have been monarchs, since in 1954, the International Code of Zoological Nomenclature, in its Opinion 282, decided that specimens thought to be monarchs originating from East Asia were not members of the same species as those originating from North America. The East Asian species was nonetheless determined to be a member of the same genus as the monarch - Danaus - and was given the name 
Danaus genutia. The North American species - the actual monarch - retained the designation Danaus plexippus (Hamm, 2017). Hamm believed that because the researchers conducted the study in India and reported that they captured their specimens outside their building, they analyzed specimens of Danaus genutia. Hamm conducted his own study using similar methods to Rao and Murty and concluded that the monarch butterfly only has 28 chromosomes. This finding is additional evidence that the butterflies studied by Rao and Murty were not monarchs.

If we reconstruct the episode from Hamm's perspective, he rejected Rao and Murty's assumption that the butterflies collected in Guntur, India were monarchs as well as their conclusion that monarchs have 30 chromosomes. In this case, we have a simple replacement of first-order propositions with other first-order propositions:

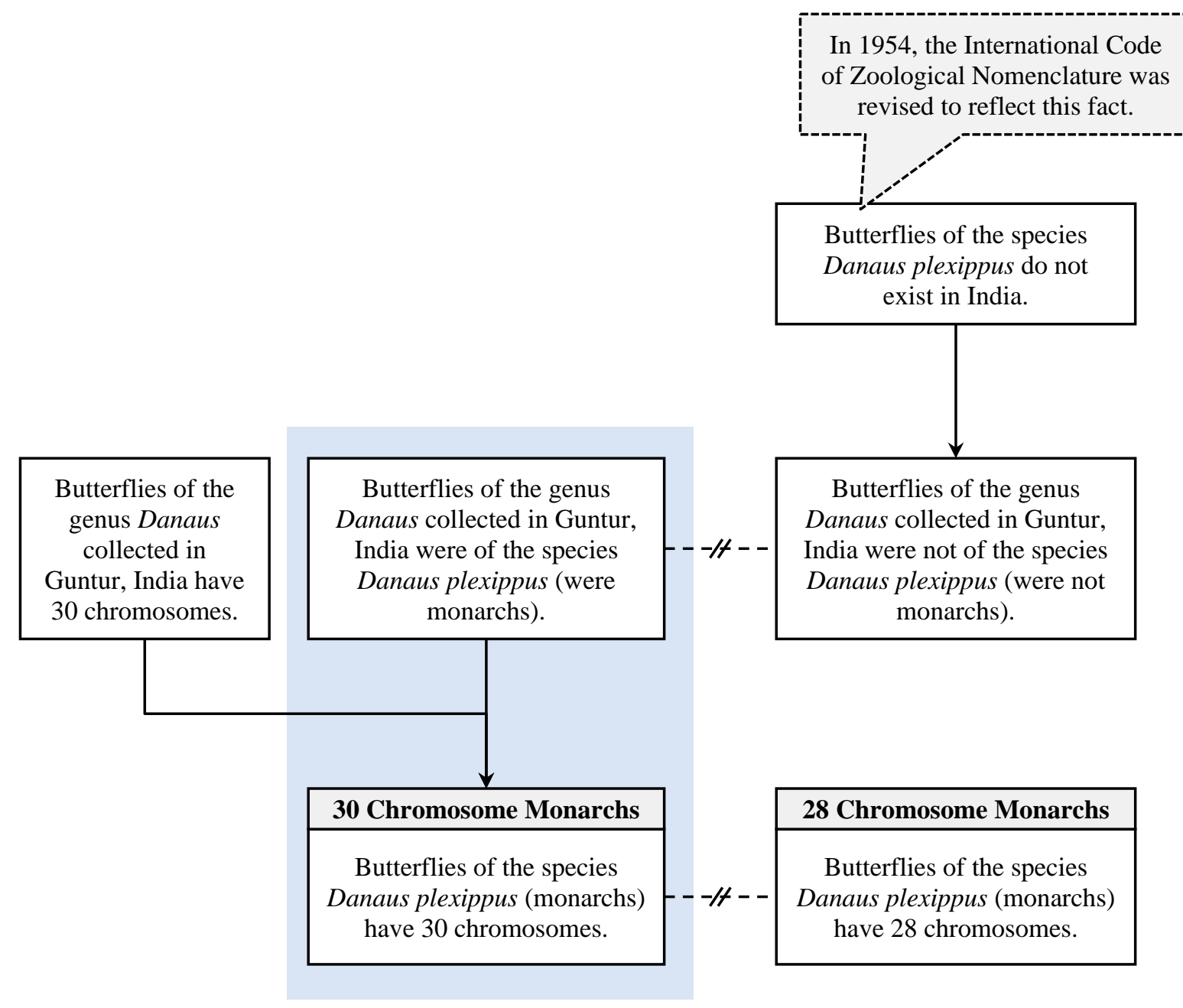

Now, even if Hamm did not conduct his own study to establish that the monarch butterfly only has 28 chromosomes but merely showed that the butterflies studied by Rao and Murty were misidentified, the case would still be in accord with the theory rejection theorem. In that hypothetical scenario, it would be similar to the pulsar planet case where the first-order proposition was replaced by the second-order proposition stating that there is no sufficient reason for accepting the first-order proposition. The following diagram depicts that hypothetical scenario: 


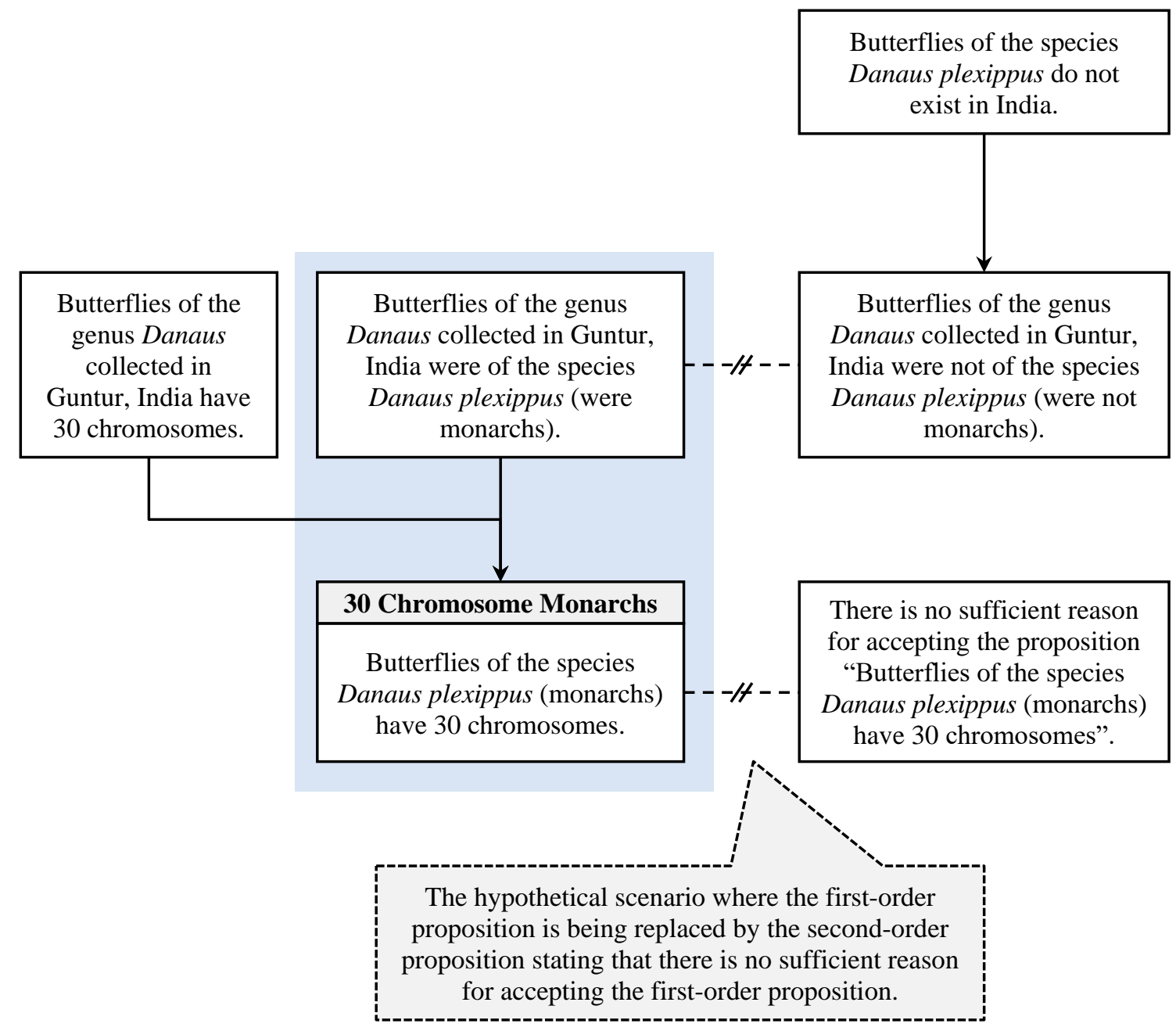

In this hypothetical scenario, the second-order proposition would be a deductive consequence of the premise that Rao and Murty's study was the only reason to accept the proposition that monarchs have 30 chromosomes and the premise that the proposition "Butterflies of the genus Danaus collected in Guntur, India were of the species Danaus plexippus (were monarchs)" is not acceptable:

The only reason for the proposition "Butterflies of the species Danaus plexippus (monarchs) have 30 chromosomes" is the conjunction of the propositions "Butterflies of the genus Danaus collected in Guntur, India were of the species Danaus plexippus (were monarchs)" and "Butterflies of the genus Danaus collected in Guntur, India have 30 chromosomes".
The proposition "Butterflies of the genus Danaus collected in Guntur, India were of the species Danaus plexippus (were monarchs)" is not acceptable.

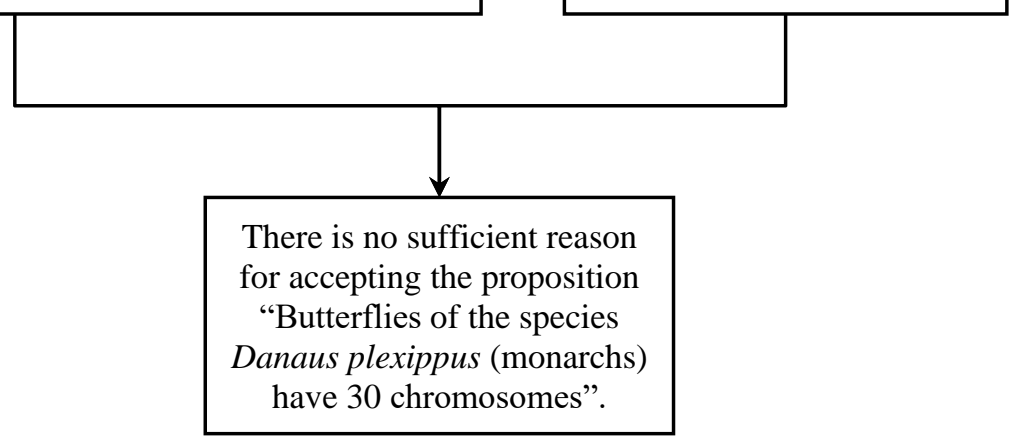


It is important to repeat that our analysis of the case was from the perspective of Hamm's mosaic. As for the broader genetics community, Hamm's findings currently remain unaccepted, as evidenced by the fact that his paper remains in pre-print. Meanwhile, other papers continue to take the theory that monarch butterflies have 30 chromosomes as an accepted theory (Price, 2017). For example, an accepted paper published in November 2017 entitled "Karyotypes versus Genomes: The Nymphalid Butterflies Melitaea cinxia, Danaus plexippus, and D. chrysippus" continues to cite 30 as the number of chromosomes for Danaus plexippus (Traut, Ahola, Smith, Gordon, \& ffrench-Constant, 2017). Thus, at present, the broader community's assessment of Hamm's findings has not yet reached an outcome. Nonetheless, regardless of the outcome, this case, like the first one, would give no reason to question the theory rejection theorem.

\section{Piltdown Man}

Our last example - the Piltdown Man - is arguably one of the most famous instances of fraud in the history of science. The Darwinian theory of evolution states that new species arise by physical descent from other species. Such changes are fueled by the mechanism of natural selection, a process in which organisms with traits that are advantageous in a particular environment are more likely to survive and produce offspring bearing those favored traits (Darwin, 1859; Dawkins, 1997; DeWitt, 2010, pp. 297). Darwin's accepted theory implies that, since human beings are a species, they should have also evolved by natural selection from some pre-existing species by a gradual process of change. In the nineteenth century, comparative anatomical evidence indicated that humanity's closest living relatives were the great apes, suggesting that humans and the modern great apes evolved from a common ape-like ancestor. This theory could be tested by finding the fossilized remains of human ancestors with ape-like traits, and thus great importance was attached to this search. Neanderthal and Homo erectus fossils that fit such expectations were discovered in the late nineteenth century (Dorey, 2018).

By the early twentieth century, anthropological discoveries were on the rise in Europe, including the discovery of the Heidelberg jaw in 1907. Having already made significant contributions to the British Museum's fossil collection, the notable anthropologist Charles Dawson was looking to join in on the search for the remains of early humans (Thomson, 1991). Between 1906 and 1911, Dawson and his team claimed to have collected pieces of a human skull and jaw at a site in Piltdown, Sussex. In 1912, Dawson announced his discovery of the remains of the Piltdown Man at a meeting of the Geological Society in London (Donovan, 2016). His discovery was published the following year (Dawson \& Woodward, 1913). The newly discovered primitive "dawn man" was named Eoanthropus dawsoni - Latin for "Dawson's dawn man". The skull gained fame in the anthropological community and beyond, even being regarded as "the jewel in the crown of British paleoanthropology for 40 years" (Thomson, 1991; Donovan, 2016). Shortly after the discovery was announced, casts of the fossils were made. These casts were examined by the greater archaeological community (Thomson, 1991). Anthropologist Arthur Keith and geologist Arthur Woodward reconstructed the remains to produce two very different skulls; one appeared modern and the other more primitive (Thomson, 1991). There was some debate and doubt over whether the jaw fit with the reconstructions of the skull, but the existence of Piltdown Man remained accepted by the broader community (including Keith and Woodward).

In 1917, the discovery of three fragments of a second Piltdown skull (Piltdown II) was formally announced, just five months after Dawson's death. The discovery helped silence some of the skeptics of Piltdown Man's existence, including accusations from William King Gregory of the American Museum of Natural History, zoologist Gerrit Miller of the U.S. National Museum of Natural History, and others that the Piltdown Man was a hoax (Thomson, 1991). It is important to note that the existence of Piltdown Man was still widely accepted, as seen in the biology textbooks of the 1930's and 1940's. In these textbooks, the characteristics of the Piltdown Man and its role in the human fossil record were discussed (Skoog, 2005; Smallwood, Reverley, \& Bailey, 1934). In short, despite some uncertainties, the theory that the cranium and jaw that Dawson and Woodward (1913) said they found in Piltdown gravel belonged to a Pleistocene human ancestor was accepted by the anthropological 
community for nearly 40 years. The argument supporting this acceptance, as originally presented in Dawson and Woodward (1913), is diagrammed below:

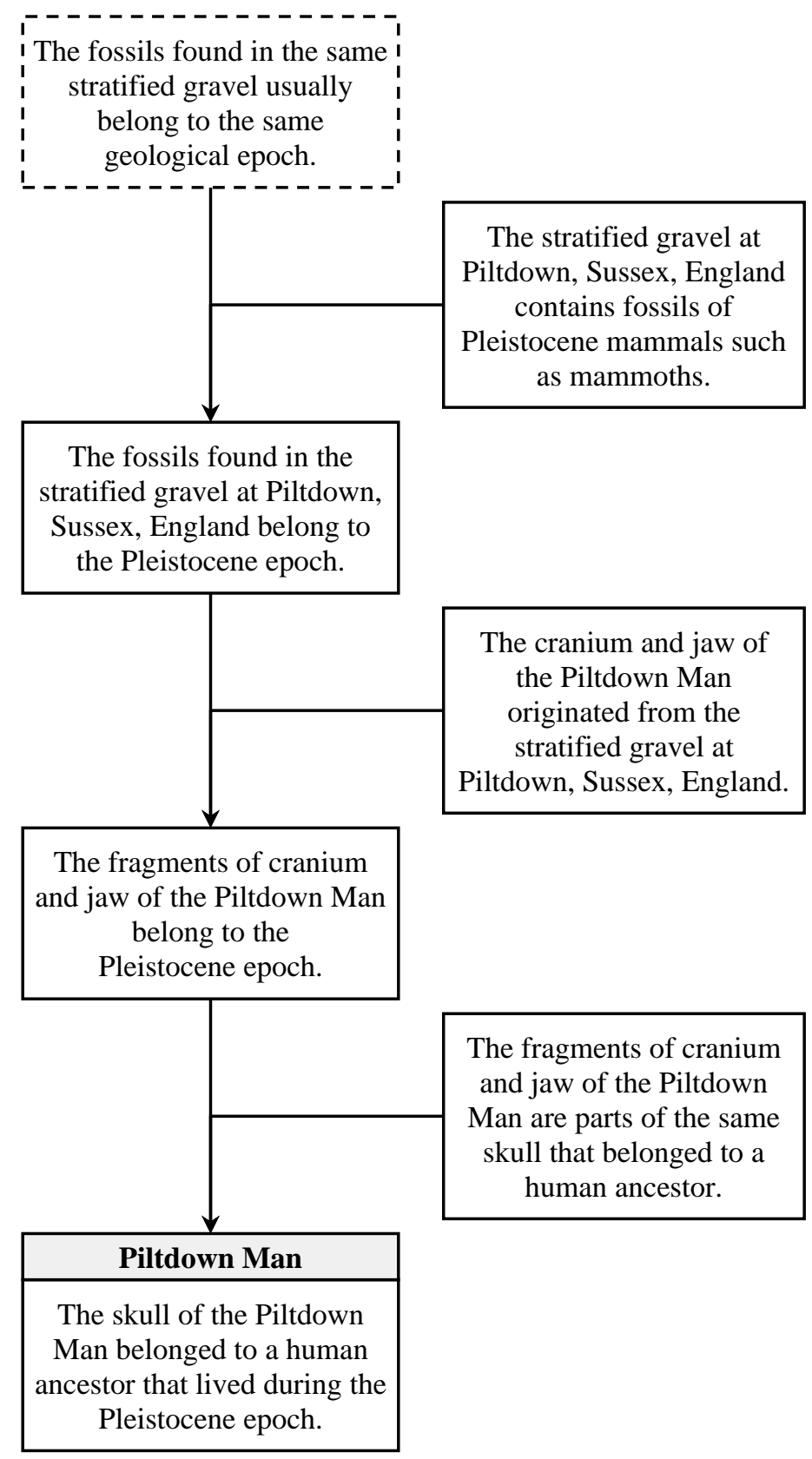

As can be seen, the argument supporting the conclusion that the skull of the Piltdown Man belongs to a human ancestor that lived during the Pleistocene epoch involves several explicit premises. The first is that the stratified gravel at Piltdown, Sussex, England contains many fossils of Pleistocene mammals such as woolly mammoths. Combined with an implicit premise that the fossils found in the same stratified gravel usually belong to the same geological epoch, it leads to the proposition "The fossils found in the stratified gravel at Piltdown, Sussex, England belong to the Pleistocene epoch". The second premise is that the fragments of cranium and jaw of the Piltdown Man do indeed originate from the stratified gravel at Piltdown, Sussex in the UK, where they were reported to have been discovered. Finding the cranium and jaw in this gravel would imply that they also date to the Pleistocene. The third premise is that the fragments of cranium and jaw, having been found together, derived from a single species, which would then have to have been a human ancestor with an ape-like jaw and a human- 
like cranium. Together with the proposition "The fragments of cranium and jaw of the Piltdown Man belong to the Pleistocene epoch" it implies that the skull belonged to a species of prehistoric human ancestor that lived during the Pleistocene epoch. As before, the diagram presents a mere sketch of a more complex argument that actually buttressed the acceptance of Piltdown Man.

As the 1950s approached, some members of the anthropological community remained unconvinced of the authenticity of Dawson's findings. Kenneth Oakley, the head of anthropology at the British Museum, was one of these members. He analyzed the fossils from the first Piltdown site and found that the jaw was not as old as originally claimed. Along with Oxford scientists Joseph Weiner and Wilfred LeGros Clark, Oakley continued to pursue the theory that Dawson or some member of his team had fabricated the fossils of the Piltdown Man (DeGroote et al., 2016). They subjected the samples from the Piltdown specimens to a number of chemical tests aimed at determining their age. Fluorine and nitrogen tests showed the cranial fragments and jaw to be of different ages, and the jaw to be recent (Oakley \& Weiner, 1955; Weiner \& Oakley, 1953; Weiner, Oakley, \& LeGros Clark, 1953). Radiocarbon dating showed that both the jaw and the cranial fragments are no more than a few centuries old, and confirmed that they are not the same age (DeVries \& Oakley, 1959; Oakley, 1976). By contrast, the Piltdown gravel in which the specimens were said to have been found is of Pleistocene age and contains fossils of Pleistocene mammals. Thus, neither the jaw nor the cranial fragments could possibly have come from the Piltdown gravel where they were said to have been discovered.

The jaw was found to be anatomically identical to that of a modern orangutan (Oakley \& Weiner, 1955). Modern orangutans come from Borneo or Sumatra and were never found in England, which is further evidence that they could not have come from the Piltdown gravel (Oakley \& Weiner, 1955; Oakley, 1976). The cranial fragments are indicative of the cranium of a recent human, consistent with the radiocarbon age found for them. This is evidence that the cranial fragments and the jaw did not come from the same species, as is the fact that they are not the same age (DeVries \& Oakley, 1959; Oakley, 1976). The teeth, jaw, and cranial fragments all show signs of having been fraudulently altered. The teeth show patterns of wear that are not consistent with natural wear, but are consistent with artificial abrasion to simulate human-style wear (Oakley \& Weiner, 1955; Weiner \& Oakley, 1954; Wiener, Oakley, \& LeGros Clark, 1953). The jaw was intentionally stained with an ironcontaining paint-like substance to match the Piltdown gravel (Oakley \& Weiner, 1955; Weiner and Oakley, 1954). The staining was already present when the jaw was discovered in Woodward's presence, indicating that it may have been planted (Weiner \& Oakley, 1954). The cranial fragments were also intentionally stained (DeVries \& Oakley, 1959). This thorough analysis showed that the cranium and jaw of the Piltdown Man had been artificially stained to appear older and were composed of bones from different mammals, then eventually planted at the Piltdown sites.

The uncovering of the falsehood led to the community's rejection of the existence of Piltdown Man, as indicated by the numerous publications in the 1950s citing the inconsistencies of the discovery (Weiner, Oakley, \& LeGros Clark, 1953; Oakley \& Hoskins, 1950; Washburn, 1953; Straus, 1954; DeVries \& Oakley, 1959). While there is evidence that it was most likely Dawson who committed fraud, it is still uncertain who exactly stood behind the hoax; the list of suspects can only be narrowed down to Dawson and his research team (DeGroote et al., 2016). Regardless, the guilty party did not abide by the norms of the research process and the community erroneously accepted their theory.

As can be seen in the diagram below, all the rejected propositions of Dawson's original argument were replaced by newly accepted propositions: 


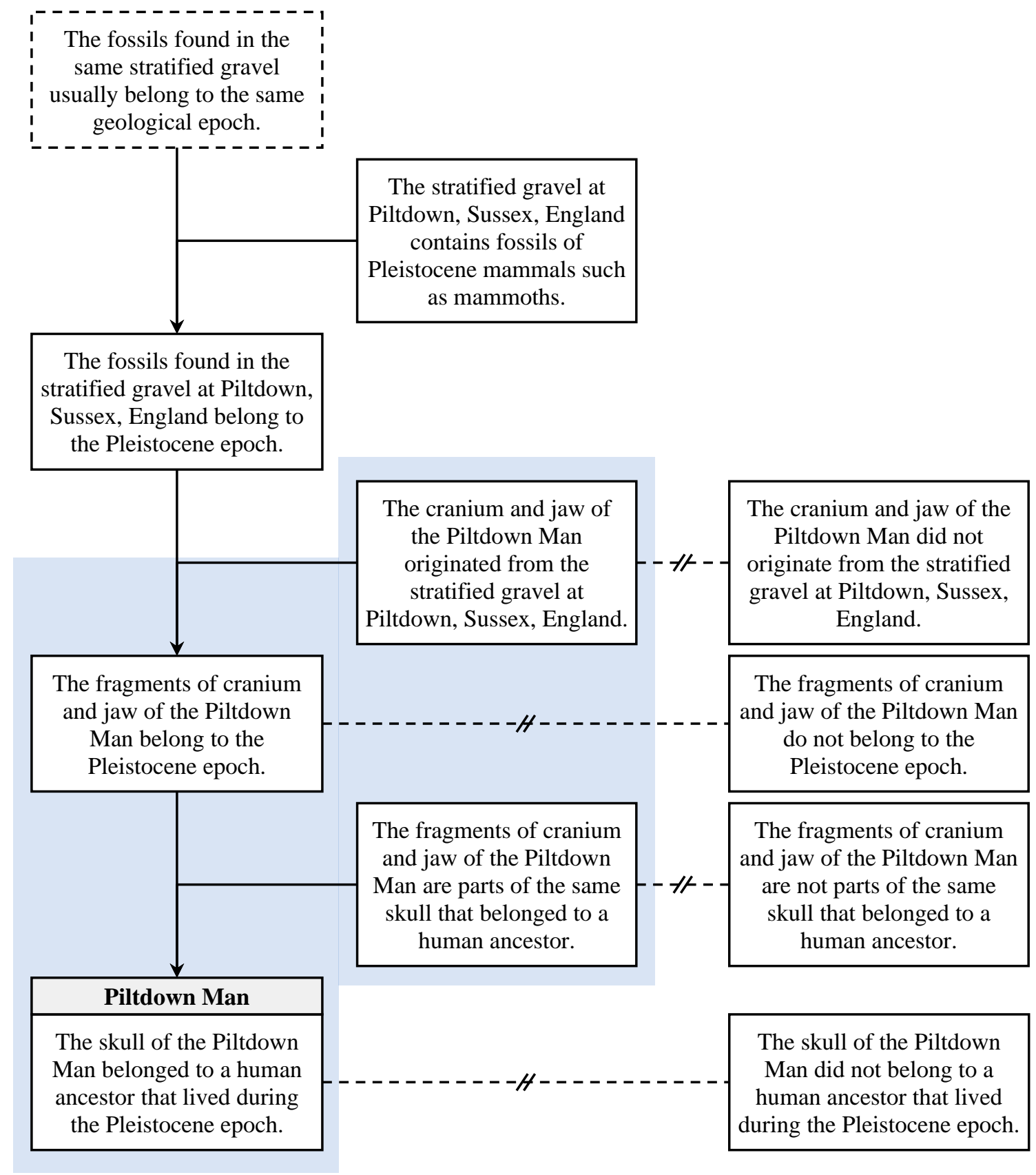

As in the case of the pulsar planet, all the rejected premises of the original argument were replaced by their respective first-order negations. Yet, unlike the previous cases, here even the conclusion was replaced by a firstorder proposition. Indeed, the new evidence provided support for a new first-order theory that states that the skull of the Piltdown Man was a modern forgery fashioned from fragments of the cranium of a modern human and the jaw of a modern orangutan and, thus, did not belong to a human ancestor that lived during the Pleistocene epoch. Because of this new first-order theory, in this case it is particularly easy to see that the way the community handled the discovery of the error was fully consistent with the theory rejection theorem.

\section{Conclusion}

Error is a common part of scientific practice, which must be accounted for by scientonomy. We began by providing a formal scientonomic definition of error in order to clearly identify the phenomenon. We then used this definition to identify a number of sample instances of scientific error from the history of science for in-depth study in order to better understand the way in which errors are handled. In our analysis, we found the need to 
focus on individual propositions that pushed the propositions of original arguments out of their respective mosaics. In these arguments, some theories served as premises, providing sufficient reason to accept another theory or theories as conclusions. The premises of such arguments can typically themselves be regarded as conclusions of technical arguments, regarding such things as mathematical models of the motions of the Earth through space, or the taxonomic identification of a butterfly. We found that when error is recognized, one or more of the key premises of such an argument are replaced by new propositions incompatible with them. Despite concerns raised in the past, our analysis shows that scientific error handling, when properly analyzed, is compatible with the currently accepted theory rejection theorem.

We have shown that, in some cases, the conclusion of an original argument is being replaced by a secondorder proposition stating the lack of sufficient reason for accepting that conclusion. The role of reasons is made evident by our analysis of cases of scientific error and the consequences of detection of the error. There seem to be specific reasons as to why an agent accepts and/or rejects a theory, and this is made evident by our analysis of instances of error. In particular, the rejection and replacement of a theory or theories which serve as a premise or premises for another theory leads to the rejection of that theory because those premises were the agent's reason for accepting that theory in the first place. These findings further highlight the importance of the concepts of reason and sufficient reason introduced by Palider (2019).

\section{Suggested Modification}

We suggest the following modification:

\section{[Sciento-2021-0003]}

Accept the following definition of error:

- Error $\equiv$ An epistemic agent is said to commit an error if the agent accepts a theory that should not have been accepted given that agent's employed method.

\section{Error $\equiv$}

An epistemic agent is said to commit an error if the agent accepts a theory that should not have been accepted given that agent's employed method.

\section{[Sciento-2021-0004]}

Provided that the previous modification is accepted, accept that the handling of scientific error as defined above is compatible with the theory rejection theorem.

\section{References}

Allchin, D. (2001). The Epistemology of Error. Unpublished Manuscript. Retrieved from http://douglasallchin.net/papers/epist'of.pdf.

Anonymous (1992). The Planet Vanishes. Nature 355, pp. 187-188.

Bailes, M.; Lyne, A. G.; \& Shemar, S. L. (1991). A Planet Orbiting the Neutron Star PSR1829-10. Nature 352, pp. 311-313.

Barseghyan, H. (2015). The Laws of Scientific Change. Springer.

Brainard, J. \& You, J. (2018). What a Massive Database of Retracted Papers Reveals About Science Publishing's 'Death Penalty'. Science 25(1), pp. 1-5.

Dawson, C. \& Woodward, A. S. (1913). On the Discovery of a Palæolithic Human Skull and Mandible in a Flint-bearing Gravel Overlying the Wealden (Hastings Beds) at Piltdown, Fletching (Sussex). Quarterly Journal of the Geological Society 69, pp. 117-123.

Dawson C. \& Woodward, A. S. (1915). On a Bone Implement from Piltdown (Sussex). Quarterly Journal of the Geological Society 71, pp. 144-149. 
DeGroote, I.; Flink, L. G.; Abbas, R.; Bello, S. M.; Burgia, L.; Buck, L. T.; \& Stringer, C. B. (2016). New Genetic and Morphological Evidence Suggests a Single Hoaxer Created 'Piltdown Man'. Royal Society Open Science 3(8), 160328.

DeVries, H. \& Oakley, K. P. (1959). Radiocarbon Dating of the Piltdown Skull and Jaw. Nature 184, pp. 224-226.

DeWitt, R. (2010). Worldviews: An Introduction to the History and Philosophy of Science (2nd ed.). John Wiley \& Sons.

Donovan, S. K. (2016). The Triumph of the Dawsonian Method. Proceedings of the Geologists' Association 127(1), pp. 101-106.

Dorey, F. (2018). A Timeline of Fossil Discoveries. The Australian Museum. Retrieved from https://australianmuseum.net.au/learn/science/human-evolution/a-timeline-of-fossil-discoveries/

Dyer, O. (2015). University of Toronto Researcher Resigns Over "Systematic" Data Fraud. BMJ 351, h6097.

Ewuoso, O. C. (2018). Misconduct vs. Honest Errors: Should Honest Errors in Research be Punished? Biomedical Journal of Scientific \& Technical Research 8(5), pp. 6757-6761.

Fraser, P. T. \& Sarwar, A. (2018). A Compatibility Law and the Classification of Theory Change. Scientonomy 2, pp. 67-82. Retrieved from https://scientojournal.com/index.php/scientonomy/article/view/31278.

Hamm, C. A. (2017). Chromosome Number of the Monarch Butterfly, Danaus plexippus (Linnaeus 1758) and the Danainae. bioRxiv. Retrieved from https://www.biorxiv.org/content/10.1101/107144v2.full.pdf.

Jamal, S. A.; Hamilton, C. J.; Eastell, R.; \& Cummings, S. R. (2011). Effect of Nitroglycerin Ointment on Bone Density and Strength in Postmenopausal Women: A Randomized Trial. JAMA 305(8), pp. 800-807.

Karamehmetoglu, S. \& Mirkin, M. (2018). Error Handling. Unpublished Manuscript.

Lyne, A. G. \& Bailes, M. (1992). No Planet Orbiting PSR1829-10. Nature 355, p. 213.

Morison, I. (2008). Introduction to Astronomy and Cosmology. John Wiley \& Sons.

Oakley, K. (1976). The Piltdown Problem Reconsidered. Antiquity 50(197), pp. 9-13.

Oakley, K. P. \& Hoskins, C. R. (1950). New Evidence on the Antiquity of Piltdown Man. Nature 165, pp. 379-382.

Oakley, K. P. \& Weiner, J. S. (1953). Chemical Examination of the Piltdown Implements. Nature 172, p. 1110.

Oakley, K. P. \& Weiner, J. S., (1955). Piltdown Man. American Scientist 43(4), pp. 573-583.

Palider, K. (2019). Reasons in the Scientonomic Ontology. Scientonomy 3, pp. 15-31. Retrieved from https://scientojournal.com/index.php/scientonomy/article/view/33557.

Palus, S. (2015). JAMA Retracts Osteoporosis Paper with Manipulated Data. Retraction Watch. Retrieved from http://retractionwatch.com/2015/12/29/jama-retracts-osteoporosis-paper-with-manipulated-data/

Patton, P.; Overgaard, N.; \& Barseghyan, H. (2017). Reformulating the Second Law. Scientonomy 1, pp. 29-39. Retrieved from https://www.scientojournal.com/index.php/scientonomy/article/view/27158.

Price, M. (2017). Monarch Miscalculation: Has a Scientific Error About the Butterflies Persisted for More than 40 years? Science Mag. Retrieved from https://www.sciencemag.org/news/2017/02/monarch-miscalculation-has-scientific-errorabout-butterflies-persisted-more-40-years.

Rao, N. \& Murty, A. S. (1975). Chromosome Number of Danaus plexippus (Lepidoptera: Danaidae). Current Science 44, pp. 894-895.

Resnik, D. B. \& Stewart, C. N. (2012). Misconduct versus Honest Error and Scientific Disagreement. Accountability in Research 19(1), pp. 56-63.

Sebastien, Z. (2016). The Status of Normative Propositions in the Theory of Scientific Change. Scientonomy 1, pp. 1-9. Retrieved from https://www.scientojournal.com/index.php/scientonomy/article/view/26947.

Shuchman, M. (2016). Misconduct Saga Rattles Bone Scientists. CMAJ: Canadian Medical Association Journal 188(13), pp. $938-939$.

Skoog, G. (2005). The Coverage of Human Evolution in High School Biology Textbooks in the $20^{\text {th }}$ Century and in Current State Science Standards. Science \& Education 14(3), pp. 395-422.

Smallwood, W.; Reverley, I.; \& Bailey, G. (1934). New Biology. Allyn \& Bacon Inc.

Straus, W. (1954). The Great Piltdown Hoax. Science 119(3087), pp. 265-269.

Thomson, K. S. (1991). Marginalia: Piltdown Man: The Great English Mystery Story. American Scientist 79(3), pp. 194201.

Traut, W.; Ahola, V.; Smith, D. A. S.; Gordon, I. J.; \& ffrench-Constant, R. H. (2017). Karyotypes versus Genomes: The Nymphalid Butterflies Melitaea cinxia, Danaus plexippus, and D. chrysippus. Cytogenetic and Genome Research 153(1), pp. 46-53.

Washburn, S. (1953). The Piltdown Hoax. American Anthropologist 55(5), pp. 759-762.

Weiner, J. S.; Oakley, K.P.; \& LeGros Clark, W. E. (1953). The Solution of the Piltdown Problem. Bulletin of the British Museum (Natural History) Geology 2(3), pp. 141-146. 